\title{
SPATIOTEMPORAL DISTRIBUTION CHARACTERISTICS OF WINTER WHEAT (TRITICUM AESTIVUM L.) WATER REQUIREMENTS AND ITS CLIMATIC DRIVING FACTORS DURING A LONG-TERM PERIOD (1969-2019): A STUDY OF SHANDONG PROVINCE, CHINA
}

\author{
Cong, X. - Kong, K. - XU, J. - XU, Z. H. - WANG, R. Z. - JiAO, Z. - ZhANG, H. W. \\ School of Water Conservancy and Environment, University of Jinan, Jinan 250022, PR China \\ (e-mail: congxin1994@126.com) \\ ${ }^{*}$ Corresponding author \\ e-mail:xu4045@126.com; phone:+86-186-6898-0091
}

(Received 24 $4^{\text {th }}$ Oct 2020; accepted 21 ${ }^{\text {st }}$ Dec 2020)

\begin{abstract}
Understanding the change of water requirement (ET) for crop production under climate change can provide scientific support for the management of agricultural water resources. The objective behind this study was to analyze spatiotemporal distribution characteristics of $E T$, effective rainfall $\left(P_{e}\right)$, irrigation requirement $(I R)$ and aridity index $(A I)$ of winter wheat, and evaluate the driving force of $E T$ changes as a result of the variation of climatic factors. Daily meteorological data from 18 meteorological stations from 1969 to 2019 distributed throughout Shandong Province, China were collected. Five climatic variables including maximum daily temperature $\left(T_{\max }\right)$, minimum daily temperature $\left(T_{\min }\right)$, relative humidity $(R H)$, wind speed $(W S)$, and sunlight hours $(S H)$, were selected to identify their contribution to the variability of $E T$. Results indicated that (1) ET distribution differed significantly both in temporal and spatial scale on a general, and decreased $-14.11-3.88 \mathrm{~mm} \mathrm{decade}^{-1}$. (2) $T_{\max }$ was the most influential climatic variable related to $E T$ variability with sensitivity coefficient of 0.36 , followed by $R H(-0.34), S H(0.13), W S(0.11)$ and $T_{\text {min }}$ (-0.07). (3) Declines of $W S$ and $S D$ were indicated by the decrease of $E T$ while the increase of $T_{\max }$ and the decrease of $R H$ contributed to enhancing $E T$.
\end{abstract}

Keywords: water requirement, effective precipitation, irrigation requirement, Mann-Kendall, spatiotemporal characteristics, sensitivity analysis, winter wheat

\section{Introduction}

At present, climate change and freshwater shortage have been regarded as the two most important global issues (Wu et al., 2019). China is a grain-producing country, generating more than half of the world's wheat and corn (Yin et al., 2016). In modern China, the shortage of water resource turns to be the biggest constraint of the agricultural development (Zhang et al., 2018). For example, the major grain producing provinces of China, Henan and Shandong, have both been facing significant trend of decreasing total water resources since the 21st century (Wu et al., 2020). Worse, with global warming due to climate change, irrigation requirements are increasing (Yuan et al., 2015). This creates a huge gap between the supplied and required agricultural water resources.

Crop water requirement $(E T)$ is considered as an important basis for planning and design of irrigation water management, which is different due to the influence of soil, climate, crop growth status and management methods. In recent years, extensive research has aimed at exploring the spatial and temporal characteristics of ET and the effects of climate on ET. Sun et al. (2013) analysed the ET data of winter wheat at 356 stations in China from 1961 to 2010, and concluded that the water demand of winter wheat (Triticum aestivum L.) in the whole growth period showed a downward trend in recent 50 years. Liu and Lin (2004) 
studied the influence of climate warming on water demand of main crops in North China. They thought that climate warming had the greatest impact on water demand of winter wheat, followed by cotton and summer maize. Gao et al. (2019) determined the impacts of climate change on crop water requirements in the double cropping system in Northern China using the annual accumulated temperature above $0^{\circ} \mathrm{C}$.

In this study, Shandong Province was selected as the research object. The winter wheat planting area of Shandong is maintained at $2 \times 10^{5} \mathrm{hm}^{2}$ all the year round, and the total wheat yield accounts for $18 \%$ of the national wheat output. Since the amount of precipitation is very low in most of the region during the winter wheat cropping season, irrigation is essential for wheat growth. In Shandong, drought is the impact of wheat production to enhance the first limiting factor. So, it is of great significance to study the crop water requirements in the context of climate change.

There are few synthetic studies on the spatial-temporal variation of ET on wheat and the impacts of the driving factors on ET both nationally and regionally in the main grain production area - Shandong Province, and the mechanisms responsible for changing ET remain uncertain. Given the important role of the Shandong farming region for the Chinese food security and the characteristics of little rainfall in wheat growing season, to fill this gap, this paper investigates three issues: (i) to estimate the temporal-spatial variations of $E T$, effective precipitation $\left(P_{e}\right)$, irrigation requirement $(I R)$ and aridity index $(A I)$ under a historical data (1969-2019); (ii) to quantify the contributions of climate work on ET of winter wheat; (iii) to analyse the mechanisms responsible for changing ET. The results will help understand the mechanisms of ET change caused by climate change and provide a reference for the scientific irrigation of winter wheat in Shandong Province.

\section{Materials and Methods}

\section{Study area}

Located in the eastern coast of China, the Shandong Province ranges from the latitudes of $34^{\circ} 22^{\prime} \mathrm{N}$ to $38^{\circ} 24^{\prime} \mathrm{N}$ and the longitudes of $114^{\circ} 47^{\prime} \mathrm{E}$ to $122^{\circ} 42^{\prime} \mathrm{E}$, with an area of $15.79 \times 10^{4} \mathrm{~km}^{2}$ that is covered by 15 prefecture-level cities (Fig. 1). The region is dominated by a temperate monsoon climate with a mean annual temperature range between $6^{\circ} \mathrm{C}$ and $8^{\circ} \mathrm{C}$, and a mean annual precipitation of 370.6-505.3 mm, of which approximately $70 \%$ occurs from June to September (statistics during 1969-2019). Summer high temperature and rain, sufficient light conditions are suitable for agricultural planting. The major cropping pattern is the winter wheat-summer maize double cropping system. Generally, the winter wheat is sown in early October in the previous year and harvested in early or mid-June in the following year, and the timing of sowing and harvesting for summer maize are at the end of May and September in the same year, respectively.

\section{Data and sources}

The data includes daily meteorological data and agricultural statistics data. Daily meteorological data were downloaded from the China meteorological data sharing service system (http://cdc.cma.gov.cn/), which included a total of 18 meteorological stations distributed throughout Shandong Province (Fig. 1). It includes daily maximum daily temperature $\left(T_{\max }\right)$, minimum daily temperature $\left(T_{\min }\right)$, relative humidity $(R H)$, wind speed $(W S)$, sunshine hours $(S H)$ and precipitation $(P)$. Then, the gaps of data were filled using the following strategies: (1) linear interpolation when the number of consecutive missing 
data was $<5$ and substitution with the mean value of other years when the number of consecutive missing data was $\geq 5$ for all variables except for precipitation, and (2) replacement with the value on the same day based on the nearest meteorological station for only the precipitation data. Agricultural statistics data mainly includes crop growth period, which were downloaded from agrometeorology material in China meteorological data sharing service system. In addition, the winter wheat yield of each city from 2000 to 2018 came from the Shandong Statistic Year Book.

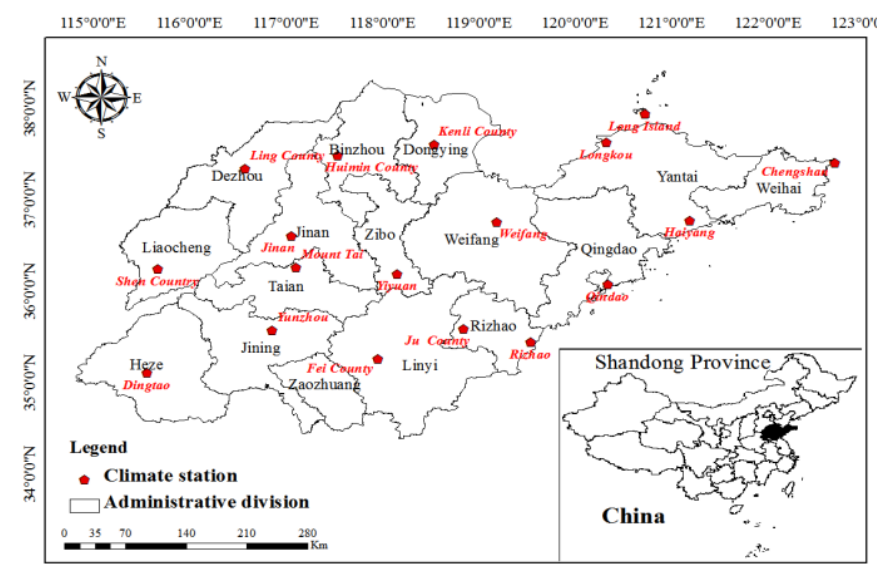

Figure 1. Location of meteorological stations in Shandong Province, China

\section{Methods}

\section{Crop water requirements (ET)}

It is calculated as the crop water requirements $\left(E T, \mathrm{~mm} \mathrm{~d}^{-1}\right)$ using the crop coefficient $\left(K_{c}\right)$ and reference evapotranspiration $\left(E T_{0}, \mathrm{~mm} \mathrm{~d}^{-1}\right)$ recommended by the FAO (Allen et al., 1998). The ET is calculated as follows (Eq. 1$)$ :

$$
E T=K_{c} \times E T_{0}
$$

The crop coefficient $K_{c}$, is defined for the initial growing stage $\left(K_{c i n i}\right)$, dormancy season $\left(K_{c d o r}\right)$, mid-season $\left(K_{c m i d}\right)$ and end-season $\left(K_{c e n d}\right)$. Notably, the crop coefficient of winter wheat over initial growing stage and the dormancy period were set to $0.6\left(K_{\text {cini }}\right)$ (Dong et al., 2013; Sun et al., 2013) and 0.4 ( $\left.K_{\text {cdor }}\right)$ (Tao et al., 2003). The values in midseason and end-season were obtained by single crop coefficient approach (Allen et al., 1998) and were listed in Table 1.

Then, based on the $K_{c i n i}, K_{c d o r}, K_{c m i d}, K_{c e n d}$ and crop phenology period, the daily crop coefficient could be computed by linear interpolation. The single crop coefficient approach was used to calculate the crop coefficients, as follows (Eq. 2):

$$
K_{c}=K_{c t a b}+\left[0.04\left(U_{2}-2\right)-0.04\left(R H_{\min }-45\right)\right]\left(\frac{h}{3}\right)^{0.3}
$$

where $K_{c t a b}$ is the crop coefficient of corresponding growth stage, $U_{2}$ is the wind speed at $2 \mathrm{~m}$ height $\left(\mathrm{m} \mathrm{s}^{-1}\right), R H_{\min }$ is the average value of daily minimum relative humidity in corresponding growth stages (\%), $h$ is the average height of crops in corresponding growth stages $(\mathrm{cm})$. 
Table 1. Growth period and crop coefficient of winter wheat

\begin{tabular}{|c|c|c|c|c|c|c|c|c|c|c|c|}
\hline \multirow{2}{*}{ Meteorological stations } & $\begin{array}{c}\text { Beginning date } \\
\text { of initial } \\
\text { growth period }\end{array}$ & $\begin{array}{c}\text { End date of } \\
\text { initial growth } \\
\text { period }\end{array}$ & \begin{tabular}{|c|} 
Beginning date \\
of dormancy \\
season
\end{tabular} & $\begin{array}{l}\text { End date of } \\
\text { dormancy } \\
\text { season }\end{array}$ & $\begin{array}{c}\text { Beginning date } \\
\text { of mid-season }\end{array}$ & $\begin{array}{l}\text { End date of } \\
\text { mid-season }\end{array}$ & Harvest date & \multirow{2}{*}{$K_{c i n i}$} & \multirow{2}{*}{$K_{c d o r}$} & \multirow{2}{*}{$K_{\text {cmid }}$} & \multirow{2}{*}{$K_{\text {cend }}$} \\
\hline & $\begin{array}{l}\text { Sowing date } \\
\text { (date/month) }\end{array}$ & $\begin{array}{l}\text { Tillering stage } \\
\text { (date/month) }\end{array}$ & $\begin{array}{c}\text { Overwintering } \\
\text { period } \\
\text { (date/month) }\end{array}$ & $\begin{array}{l}\text { Green return } \\
\text { period } \\
\text { (date/month) }\end{array}$ & $\begin{array}{l}\text { Jointing stage } \\
\text { (date/month) }\end{array}$ & $\begin{array}{l}\text { Heading date } \\
\text { (date/month) }\end{array}$ & $\begin{array}{c}\text { Mature } \\
\text { period } \\
\text { (date/month) }\end{array}$ & & & & \\
\hline Ling County & 9 October & 30 October & 3 December & $1 \mathrm{March}$ & 4.13 April & 5 May & 10 June & 0.6 & 0.4 & 1.15 & 0.4 \\
\hline Huimin & 9 October & 30 October & 3 December & $1 \mathrm{March}$ & 4.13 April & 5 May & 10 June & 0.6 & 0.4 & 1.15 & 0.4 \\
\hline Kenli & 9 October & 30 October & 3 December & $1 \mathrm{March}$ & 4.13 April & 5 May & 10 June & 0.6 & 0.4 & 1.16 & 0.4 \\
\hline Long Island & 3 October & 23 October & 14 December & 15 March & 4.16 April & 7 May & 15 June & 0.6 & 0.4 & 1.19 & 0.4 \\
\hline Longkou & 3 October & 23 October & 14 December & 15 March & 4.16 April & 7 May & 15 June & 0.6 & 0.4 & 1.19 & 0.4 \\
\hline Chengshantou & 3 October & 23 October & 14 December & 15 March & 4.16 April & 7 May & 15 June & 0.6 & 0.4 & 1.17 & 0.4 \\
\hline Shen County & 9 October & 30 October & 3 December & $1 \mathrm{March}$ & 4.13 April & 5 May & 10 June & 0.6 & 0.4 & 1.17 & 0.4 \\
\hline Jinan & 12 October & 1 November & 17 December & 27 February & 4.06 April & 28 April & 7 June & 0.6 & 0.4 & 1.17 & 0.4 \\
\hline Mount Tai & 12 October & 1 November & 17 December & 27 February & 4.06 April & 28 April & 7 June & 0.6 & 0.4 & 1.16 & 0.4 \\
\hline Yiyuan & 12 October & 1 November & 17 December & 27 February & 4.06 April & 28 April & 7 June & 0.6 & 0.4 & 1.15 & 0.4 \\
\hline Weifang & 5 October & 27 October & 17 December & 26 February & 4.07 April & 30 April & 10 June & 0.6 & 0.4 & 1.16 & 0.4 \\
\hline Qingdao & 3 October & 23 October & 14 December & 15 March & 4.16 April & 7 May & 15 June & 0.6 & 0.4 & 1.18 & 0.4 \\
\hline Haiyang & 3 October & 23 October & 14 December & 15 March & 4.16 April & 7 May & 15 June & 0.6 & 0.4 & 1.18 & 0.4 \\
\hline Dingtao & 10 October & 5 November & 17 December & 17 February & 4.01April & 24 April & 5 June & 0.6 & 0.4 & 1.15 & 0.4 \\
\hline Yanzhou & 12 October & 1 November & 17 December & 27 February & 4.06 April & 28 April & 7 June & 0.6 & 0.4 & 1.18 & 0.4 \\
\hline Fei County & 5 October & 27 October & 17 December & 26 February & 4.07 April & 30 April & 10 June & 0.6 & 0.4 & 1.18 & 0.4 \\
\hline Ju county & 5 October & 27 October & 17 December & 26 February & 4.07 April & 30 April & 10 June & 0.6 & 0.4 & 1.18 & 0.4 \\
\hline Rizhao & 5 October & 27 October & 17 December & 26 February & 4.07 April & 30 April & 10 June & 0.6 & 0.4 & 1.18 & 0.4 \\
\hline
\end{tabular}


The daily $T_{\max }, T_{\min }, R H, S H, W S$ used to calculate $E T_{0}$ using the FAO PenmanMonteith equation (Allen et al., 1998), as follows (Eq. 3):

$$
E T_{0}=\frac{0.408 \Delta\left(R_{n}-G\right)+\gamma(900 / T+273) U_{2}\left(e_{S}-e_{a}\right)}{\Delta+\gamma\left(1+0.34 U_{2}\right)}
$$

where $\Delta$ is the slope of the saturation vapor pressure-temperature curve $\left(\mathrm{kPa}^{\circ} \mathrm{C}^{-1}\right), R_{n}$ is the net radiation $\left(\mathrm{MJ} \mathrm{m}^{-2} \mathrm{~d}^{-1}\right), G$ is the soil heat flux $\left(\mathrm{MJ} \mathrm{m}^{-2} \mathrm{~d}^{-1}\right), \gamma$ is the psychrometric constant $\left(\mathrm{kPa}^{\circ} \mathrm{C}^{-1}\right), T$ is the average air temperature $\left({ }^{\circ} \mathrm{C}\right), e_{s}$ is the saturation vapor pressure $(\mathrm{kPa})$ and $e_{a}$ is the actual air vapor pressure $(\mathrm{kPa})$.

\section{Effective precipitation $\left(P_{e}\right)$}

The effective rainfall $\left(P_{e}, \mathrm{~mm}\right)$ is the fraction of the rainfall excluding surface runoff, deep percolation or evaporation, which is calculated by the US Department of Agriculture Soil Conservation, as cited by Döll and Stefan (2002). Calculated as follows (Eq. 4):

$$
\left\{\begin{array}{l}
P_{e}=P(4.17-0.2 P) / 4.17 \cdots P<8.3 \\
P_{e}=4.17+0.1 P \cdots \cdots \cdots \cdots \cdots P \geq 8.3
\end{array}\right.
$$

\section{Irrigation requirement $(I R)$}

Following FAO 46, the irrigation requirement $(I R, \mathrm{~mm})$ during the growing season is defined as the difference between the ET and the $P_{e}$ (Smith, 1992). The calculation formula is as follows (Eq. 5):

$$
I R=\left\{\begin{array}{c}
E T-P_{e} \cdots E T>P_{e} \\
0 \cdots \cdots \cdot E T \leq P_{e}
\end{array}\right.
$$

Aridity index (AI) and drought frequency $(D F)$

$A I$ is meaningful to water resource management. It is defined as the quotient of the difference between $E T$ and $P_{e}$ and ET (Shen et al., 2013). The specific calculation equation is as follows (Eq. 6):

$$
A I=\left(E T-P_{e}\right) / E T
$$

$D F$ is the number of times in a certain period that drought series accounts for the total series length, which is defined as the quotient of the $N$ and $n$ (He et al., 2017). It was calculated by using the following equation:

$$
D F=\frac{N}{n} \times 100 \%
$$

where, $N$ is the number of times of drought at a certain level in growth stage; $n$ is the length of the time series.

The division of agricultural drought grades was based on the national standard "Agricultural Drought Grades" and "Standardized Precipitation Evaporation Index (SPEI)". The detailed calculation of SPEI can be found in the Vicente-Serrano's research (2010). The SPEI calculations for this study used the computational procedures of the 
University of Nebraska approved by the World Meteorological Organization. According to the drought classification standard formulated by China Meteorological Administration, the drought grades of the region are divided, as shown in Table 2.

Table 2. Classification of agricultural drought grades based on crop deficit index

\begin{tabular}{c|c|c}
\hline Grade type & Index range of $\boldsymbol{A I}$ & SPEI \\
\hline No drought $(N D)$ & $A I \leq 35 \%$ & $S P E I \geq-0.5$ \\
Light drought $(L D)$ & $35 \%<A I \leq 50 \%$ & $-1 \leq S P E I<-0.5$ \\
Moderate drought $(M D)$ & $50 \%<A I \leq 65 \%$ & $-1.5 \leq S P E I<-1$ \\
Severe drought $(S D)$ & $65 \%<A I \leq 80 \%$ & $-2 \leq S P E I<-1.5$ \\
Extreme drought $(E D)$ & $A I>80 \%$ & $S P E I<-2$ \\
\hline
\end{tabular}

\section{Trend analysis, abrupt change detection and mapping}

The linear equation is usually used to describe the change trend of climate elements. The equation is as follows (Eq. 8):

$$
y(t)=a+b t
$$

In the formula, $t$ is the time series, $a$ is the empirical coefficient, which can be obtained by the least square method in the regression analysis method; $b$ is the trend change rate, when $b$ is positive (negative), it indicates that the air temperature elements have an increasing (decreasing) trend, and $10 \mathrm{~b}$ is the climate tendency rate, which represents the change rate of the temperature element in 10 year.

Abrupt change detection is used to check the possible change point of the time series that has an effect on the trend analysis results (Villarini et al., 2012; Gu et al., 2017). In this study, a comprehensive test about the mutation characteristics of ET, $P_{e}, I R$ and $A I$ were giving by using Mann-Kendall abrupt test and moving t-test technique. The reason for using the two methods is that moving t-test helps to deal with the multiple point mutations after using the Mann-Kendall abrupt test, which ensures the accuracy of the test results (Deng et al., 2018). Similarly, the level of significance was set to 0.05 .

The data of $E T, P_{e}, I R$ and $A I$ in wheat growth period were interpolated by inverse distance weighted interpolation (IDW) in ArcGIS 10.2 to obtain the corresponding spatial distribution.

\section{Sensitivity analysis}

In this paper, the one-at-a-time (OAT) was used to analyze the sensitivity of the $E T$ of wheat to its impact factors. The sensitivity of the ET to one factor can be expressed as (Eq.9) (Wang et al., 2019):

$$
S x_{i}=\lim _{\Delta x_{i} \rightarrow 0}\left(\frac{\Delta E T / E T}{\Delta x_{i} / x_{i}}\right)=\frac{\partial E T}{\partial x_{i}} \times \frac{x_{i}}{E T}
$$

where, $S x_{i}$ is sensitivity coefficient of the influencing factors; ET, $\Delta_{E T}$ are irrigation requirement and the change of it; $x_{i}, \Delta x_{i}$ is the influencing factors of irrigation requirement and its change. 
Previous research showed that the principal weather parameters affecting evapotranspiration were $T, R H, W S$ and radiation. By significance test, the $T_{\max }, T_{\min }, R H$, $W S, S H$ were selected for the sensitivity analysis.

\section{Results and Discussion}

\section{Characteristics of ET, $P_{e}, I R$ and $A I$}

Temporal characteristics and abrupt change

The trends of the annual ET, $P_{e}, I R$, and $A I$ of the winter wheat growth period in Shandong Province from 1969 to 2019 were shown in Fig. 2. As a whole, Shandong experienced a decrease in $E T, P_{\mathrm{e}}$ and $I R$, and $A I$ remained relatively unchanged during the study period. Further, the ranges of the variations in the $P_{e}$ were relatively small compared with the range of the $E T$ and $I R$ over the whole province. The $E T$ and $I R$ ranged from $380-475 \mathrm{~mm}$ and $242-397 \mathrm{~mm}$, respectively, with the maximum occurring in 1978 and the minimum in 1998. The $P_{e}$ ranged from 51 to $138 \mathrm{~mm}$, the maximum occurred in 2011 and the minimum occurred in 1998. The AI ranged between 0.64 and 0.88 , with the maximum occurring in 2011 and the minimum occurring in 2009. The coincidence of the occurrence time of the maximum value of each index indicated that the $I R$ and $A I$ were greatly influenced by the $E T$ and $P_{e}$.

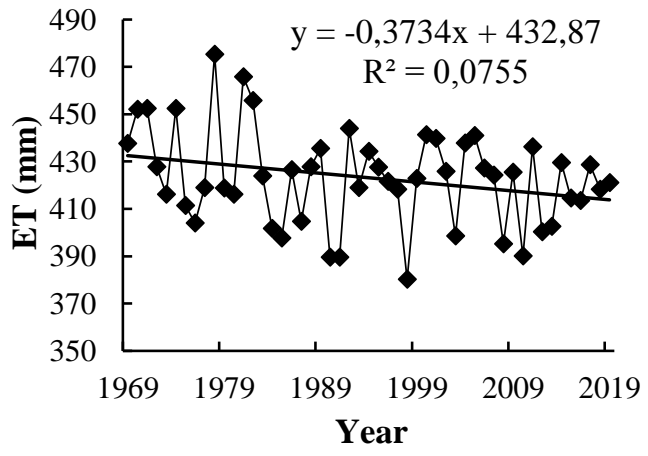

(a)

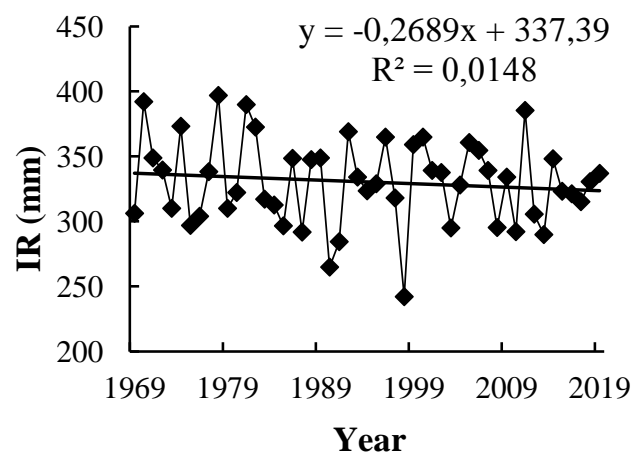

(c)

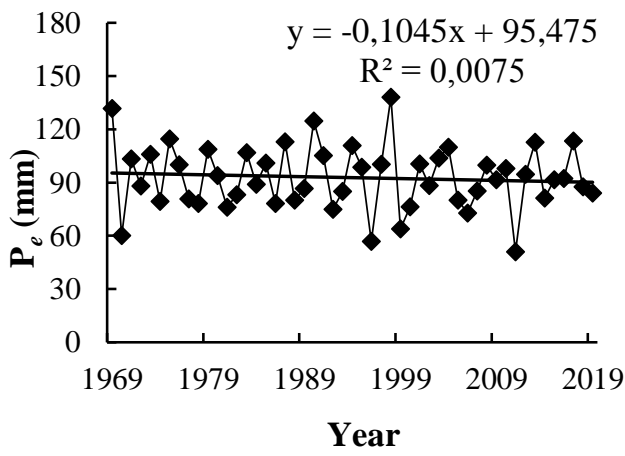

(b)

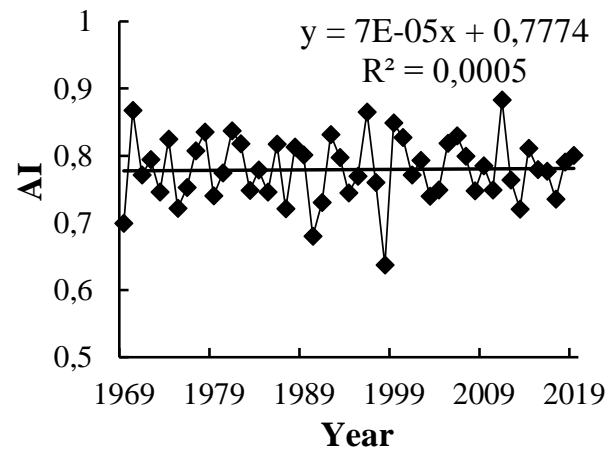

(d)

Figure 2. Interannual variation of (a) ET; (b) $P_{e} ;(c)$ IR; (d) AI in winter wheat growth period

According to Mann-Kendall abrupt test, there were seven obvious focuses in the reconfidence interval of UF and UB curves (Fig. 3a). Then, through the moving t-test, only one point was the mutation point, which was located in 1984 (Fig. 3b). This showed 
that 1984 was the abrupt change point of $E T$ from rising to decreasing. Similarly, $P_{e}, I R$ and $A I$, which have passed the Mann-Kendall abrupt test, had multiple intersections in the confidence interval between UF and UB (Fig. 3c,e,g). However, through the moving t-test, all the intersections were not abrupt points (Fig. $3 d, f, h)$.

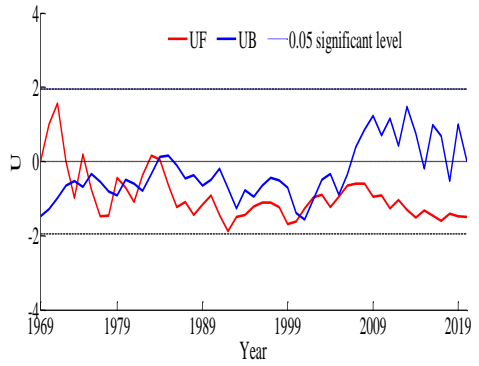

(a)

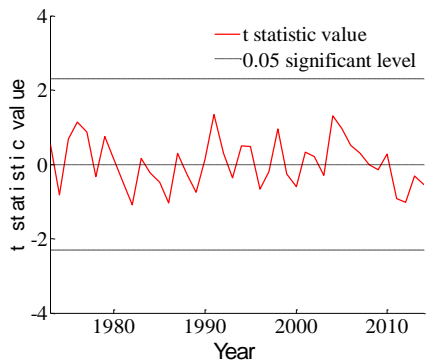

(d)

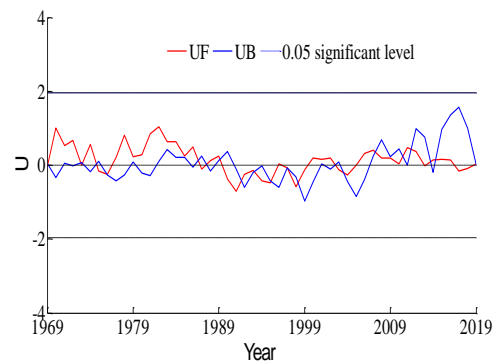

(g)

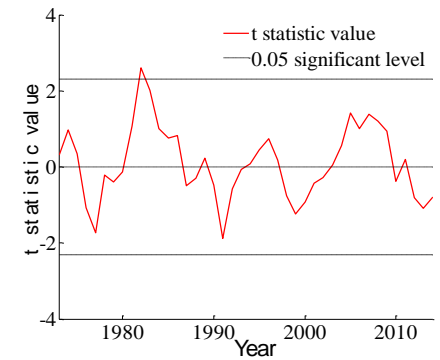

(b)

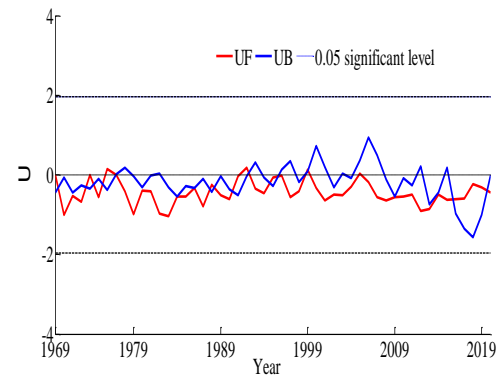

(e)

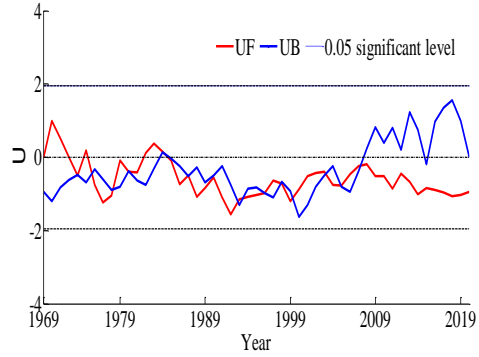

(c)

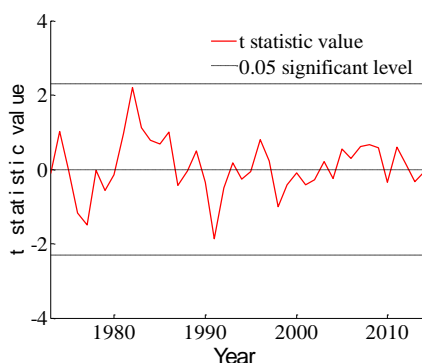

(f)

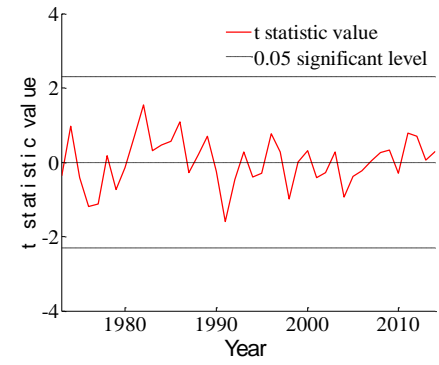

(h)

Figure 3. Time series of $(a, b) E T ;(c, d) P_{e} ;(e, f) I R ;(g, h)$ AI mutation test curve of winter wheat

In this paper, the simplified water balance formula was adopted to estimate the $E T, P_{e}$, $I R$ and $A I$ during the winter wheat growth stage in the Shandong Province, and this formula considers the $E T_{0}$ and $K_{c}$. This study showed that the ET, $P_{e}, I R$ had been downward tendency and with different degree, and $A I$ had no significant trend from 1969 to 2019. The results of this study were basically consistent with the conclusions of Ma et al. (2010). ET levels present a steady upward trend from 1969 to 1984 prior to dramatically declining. But now, the abrupt change of $E T_{0}$ levels-related research was few, the study of the abrupt change of ET levels of winter wheat was much rarer. And $E T_{0}$ was calculated by $E T$, the trend of $E T_{0}$ was similar in theory. Therefore, this paper discussed the changes of $E T_{0}$ analyzed by other scholars. Liang et al. (2010) discovered an abrupt change appeared in 1982 for annual $E T_{0}$ of the Taoer River basin of Northeast China; $E T_{0}$ levels decreased from 1961 to 1982 and then increased in China as indicated by Wang et al. (2017), and this time point was close to the time in which the valley value of annual ET happens in this study (Fig. 3). 


\section{Spatial-temporal variation}

The spatial distribution characteristics of the ET, $P_{e}, I R$ and $A I$ in Shandong Province were shown in Fig. 4. In terms of spatial variation of four indexes, in the winter wheat season, the distribution patterns of $E T$ and $I R$ were similar, they gradually decreased from the northwest to southeast, and a high-value center was located around the higher terrain area in the southwest region where the $E T$ reached $500 \mathrm{~mm}$ and $I R$ reached $400 \mathrm{~mm}$. The spatial distribution of $I R$ of winter wheat in this paper was consistent with the related research (Liu et al., 2013). There was also a remarkable gradient of distribution of $P_{e}$. It decreased from southeast to northwest, and the distribution of effective rainfall in coastal area was larger than that in inland area, and that in mountain area was larger than that in plain. The spatial pattern of $A I$ was similar to that of $E T$ and $I R$, with lower than 0.8 of $A I$ within the strip expanding from the mid-northwest of the Shandong to the Jiaodong Peninsula where the $A I$ in eastern Shandong was relatively low.
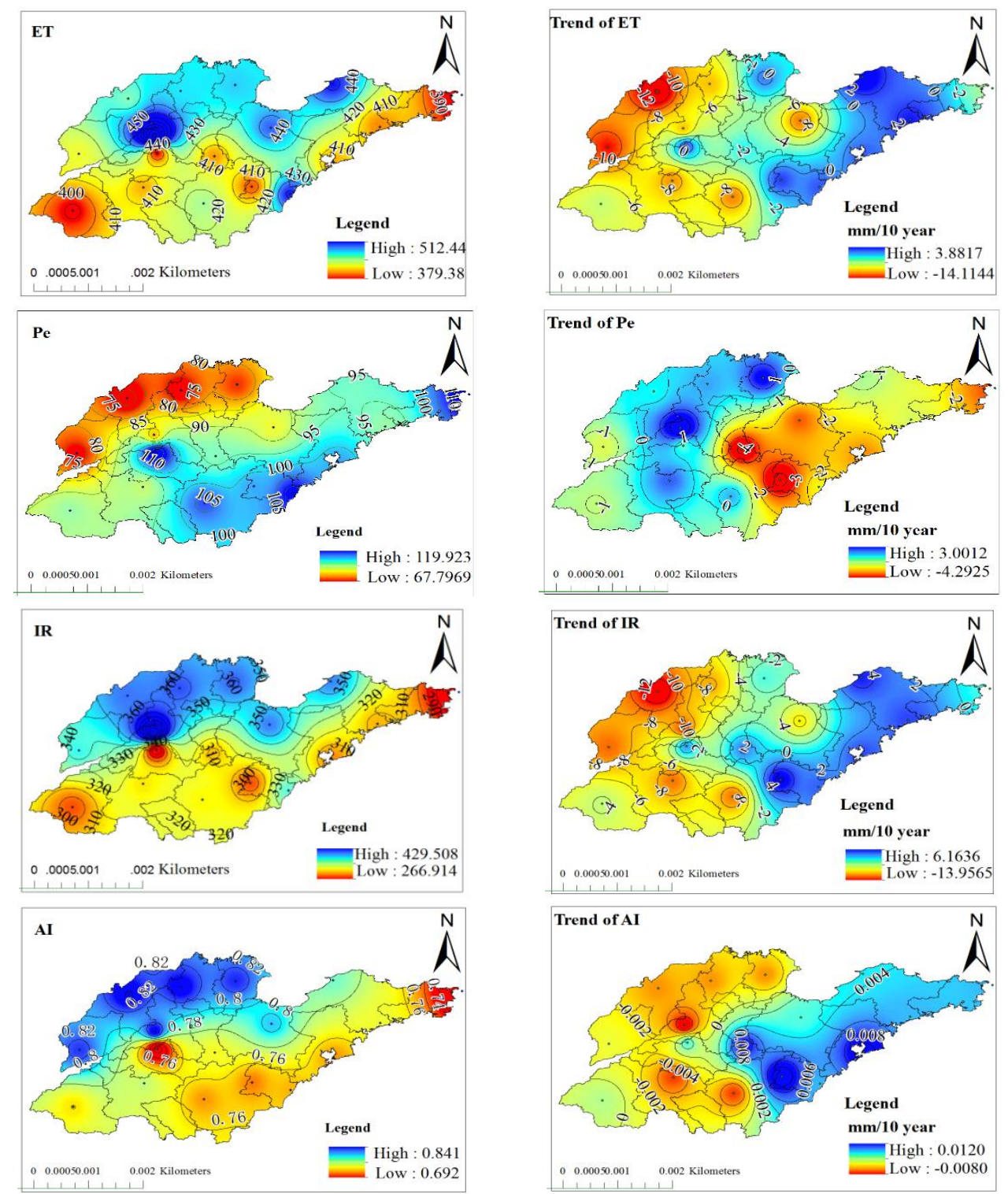

Figure 4. Spatial and temporal variation in ET, $P_{e}, I R$ and AI for winter wheat from 1969 to 
The $I R$ was calculated by combining $E T$ with $P_{e}$ together for the winter wheat growth. Nevertheless, the spatial distribution of the corresponding stations of ET and $P_{e}$ trends were distinctly different. For the four indexes, the overall spatial pattern of the trend in $I R$ was similar to that of the trend in ET. The regions with increasing $E T$ and $I R$ mainly occurred in Jiaodong Peninsula. The ET and $I R$ in the rest of the Shandong showed a decreasing trend. However, it can be clearly found that the $E T$ and $I R$ decreased with a trend of 10-12 mm decade ${ }^{-1}$ in most of northwest parts of the Shandong, within which the $E T$ and $I R$ in some regions, including the southwestern Shandong and near Bohai Bay in the middle of Shandong, decreased significantly by $2-8 \mathrm{~mm}$ decade ${ }^{-1}$. The trend of $P_{e}$ showed three zonal distributions from west to east. Among them, the $P_{e}$ decreased with a trend of $0-1 \mathrm{~mm}$ decade ${ }^{-1}$ in the central part of Shandong, while $P_{e}$ was showing an increasing trend in the rest of two regions. The increasing trend of $P_{e}$ in the east was more obvious than that in the west, with an average of $3 \mathrm{~mm}$ decade $^{-1}$. For the $A I$, the overall spatial pattern of the trend in $A I$ was similar to that of the trend in $P_{e}$. Apart from a clear reduction of the value in whole region with a decreasing trend of $A I$, only the area where the $0.01 \mathrm{~mm} \mathrm{decade}^{-1}$ rising trend in $A I$ occurred consisted of three parts, are the Jinan, the Linyi and the Jining.

On the whole, the results showed that the total effective precipitation in Shandong Province could not meet the water demand of winter wheat during the growth period, especially in the northern Shandong. The multi-year average $I R$ values in this study were $330.04 \mathrm{~mm}$ for the winter wheat. From the spatial point of view, the imbalance of precipitation and water demand in time and space leads to the aggravation of drought in northern region. Although, the result of the variation of $I R$ over Shandong in this study shows a decreasing trend (Fig. 4). On a time scale, the significantly decreasing $I R$ accompanied by significantly decreasing $E T$ and $P_{e}$ revealed that the decreasing trend of $E T$ is more significant than $P_{e}$. On a regional scale, the decline of $I R$ in western region was attributed to both the significantly decrease in $E T$ and slight increasing $P_{e}$. A decreasing pattern of water shortage for winter wheat in different regions of China can also be found in many existing studies. For example, Cao et al. (2018) have discovered the $I R$ for winter wheat in Hebei Province showed the decreasing trend with the rate of $-3.74 \mathrm{~mm}$ decade ${ }^{-1}$. Wu et al. (2020) have suggested that the water shortage for winter wheat in the north of Anhui Province decreased in a $2.0 \mathrm{~mm}$ decade $^{-1}$.

\section{Temporal-spatial distribution characteristics of drought in winter wheat growth period}

The drought in Shandong analyzed by using AI and the 9-month SPEI for the period 1969-2019 was shown in Fig. 5. In terms of drought grade, it can be seen that the relative drought degree in the north-south direction of the two methods was consistent, although the drought frequency obtained by $A I$ method was significantly higher than that by SPEI method. The frequency of drought in different grades was higher in the northwest part than in the southeast areas. The high frequency drought areas mainly occur in Dongying, Binzhou, Dezhou, Yantai and Liaocheng. It is worth noting that Xu and Han (2018) have also researched the distribution of drought frequency in Shandong Province by SPEI, and concluded that on the monthly scale, severe and above drought was higher in the north and lower in the south. The northwest of Shandong Province has large evaporation and relatively less precipitation, which is the driest climate area and high drought risk area in Shandong Province. 


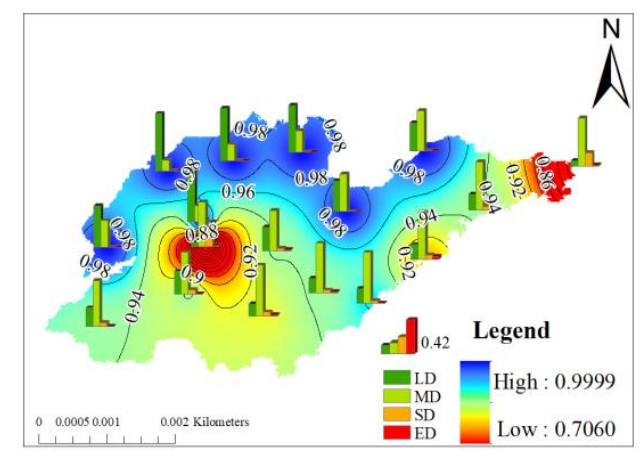

(a) AI

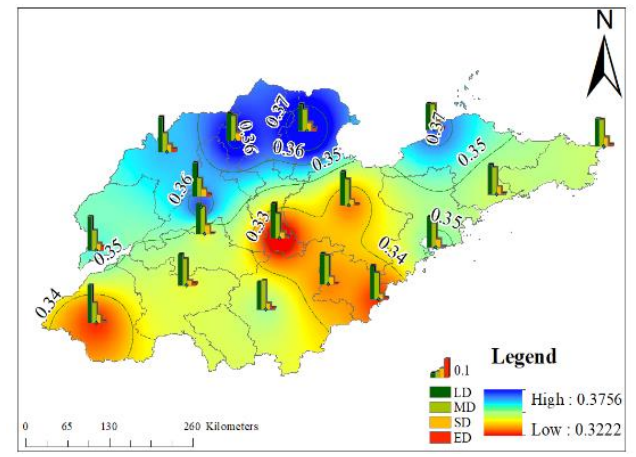

(b) SPEI

Figure 5. The spatial distribution of frequency of potential moderate and above drought in winter wheat growth from 1969 to 2019

\section{Sensitivity analysis of ET of winter wheat to meteorological factors}

Sensitivity of crop water productivity at different scale to influencing factors was analyzed by using OAT method. For the five climatic factors, in terms of Shandong Province as a whole, ET was positively correlated with $T_{\max }, W S$ and $S H$, and was negatively correlated with $T_{\max }$ and $R H$. That was, wheat $E T$ increased as $T_{\max }, W S$ and $S H$ increased, and increased as the $T_{\max }$ and $R H$ decreased. Results of sensitivity analysis for $E T$ showed that there were obvious differences between the influencing factors. $E T$ was most sensitive to $T_{\max }$ and $R H$, followed by $S H$ and $W S$. However, ET has lower sensitivity to $T_{\min }$ (Fig. 6).
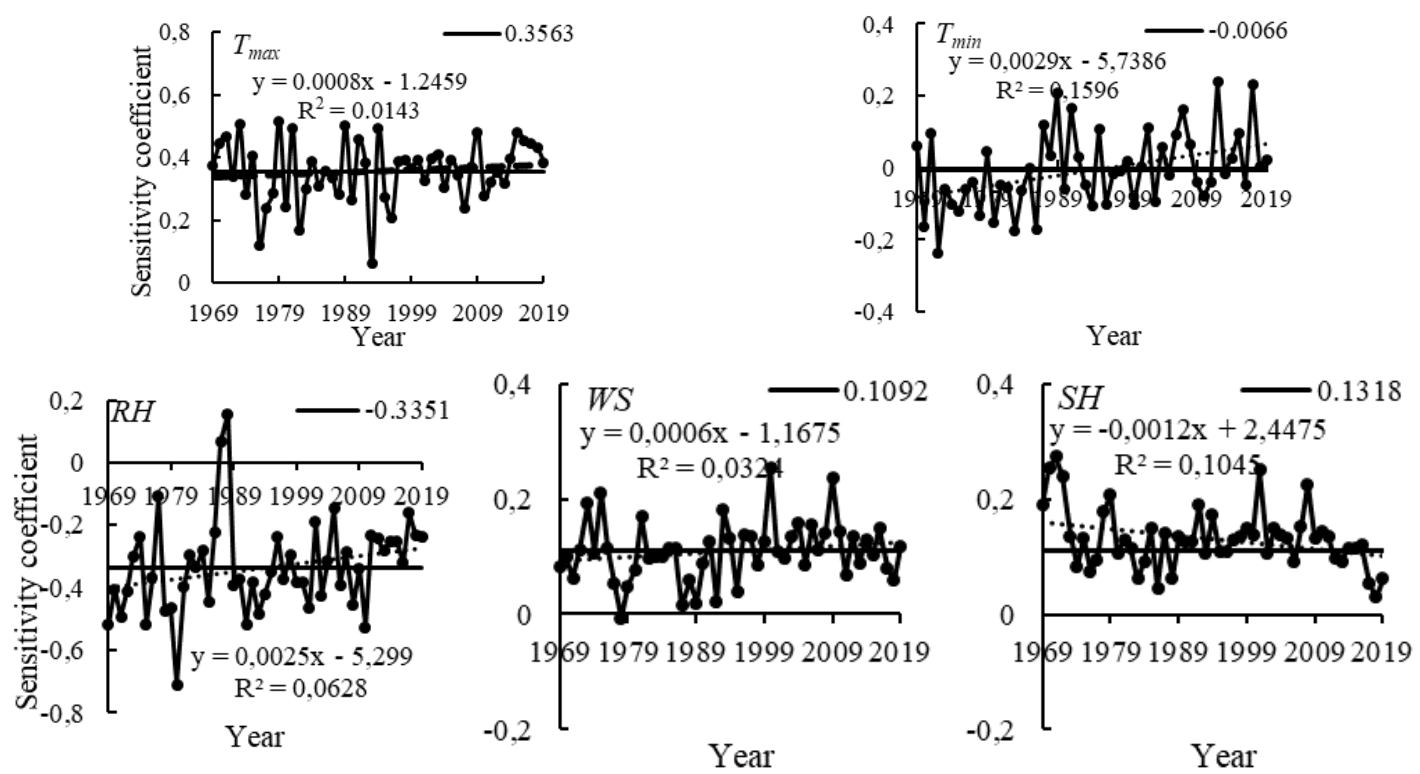

Figure 6. Annual variation of sensitivity coefficient of meteorological factors from 1969 to 2019

As observed from Fig. 7, the sensitivity coefficient of $T_{\max }\left(S T_{\max }\right)$ decreased progressively from the southwest to northeast over Shandong, reached the minimum at the mountainous and hilly area in the middle and south, and then increases in the part of the area near the Yellow Sea. The spatial distribution of the sensitivity coefficient of $T_{\min }$ 
$\left(S T_{\min }\right)$ showed a pattern that is contrary to $S T_{\max }$, and there was a discernable transition zone of $S T_{\min }$ from the southwest to northeast, expect mountainous and hilly area in the middle and south. The sensitivity coefficient of $R H(S R H)$ over Shandong was negative. Different from the distribution of other parameters, $S R H$ showed no regularity in variation of Shandong, with the largest value found in Liaocheng and the smallest value found in Weihai. The sensitivity coefficient of $W S(S W S)$ decreased progressively from the northwest to southeast over Shandong. Similar to $S W S$, the sensitivity coefficient of $S H$ $(S S H)$ decreased from northwest to southeast, with the largest value found in Taian and Jinan and the smallest value found in Rizhao and Weihai. In general, $S H$ and $W S$ were the main controlling factors in the central hilly area, and the $T_{\max }$ and $R H$ were the main control factor of $E T$ in other areas, which was consistent with the finding from north region of China (Zheng and Wang, 2015; Fan and Thomas, 2018).

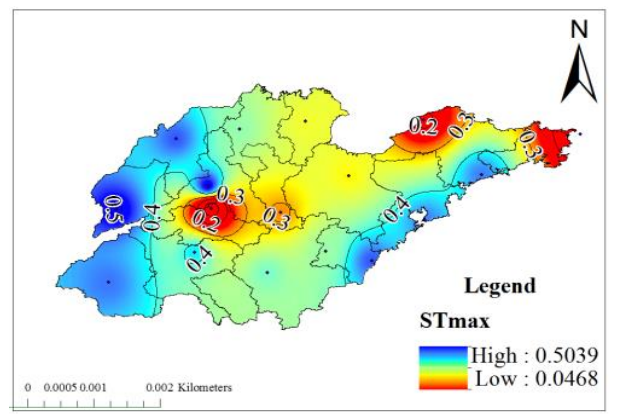

(a)

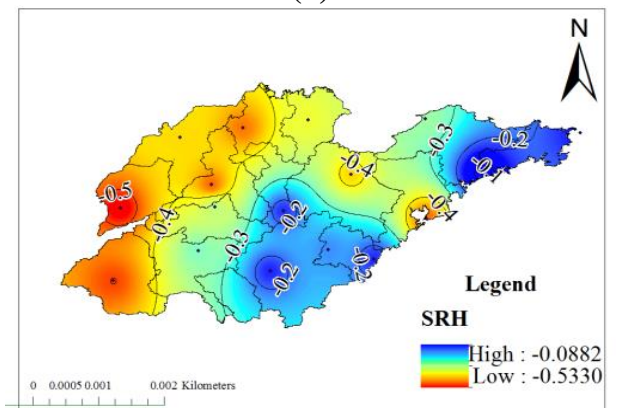

(c)

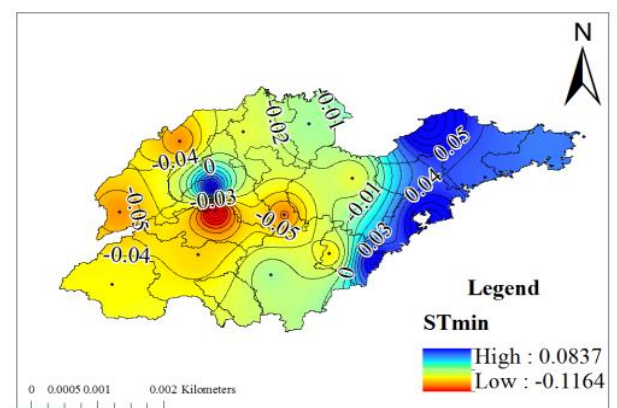

(b)

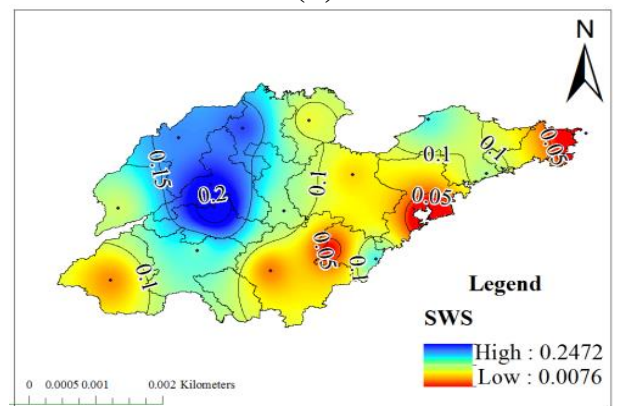

(d)

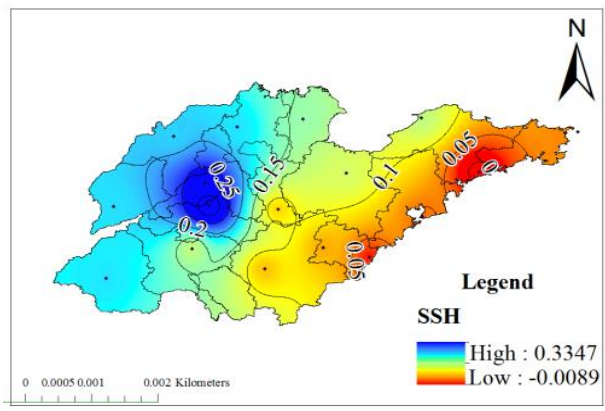

(e)

Figure 7. Sensitivity coefficients of meteorological on ET of winter wheat over Shandong from 1969 to 2019

The Fig. 7 revealed that the potential evapotranspiration of crops is positively promoted by $T_{\max }, S H$ and $W S$ and the increase of $R H$ will cause the decrease of potential evapotranspiration. The results are in line with previous studies (Liu et al., 2005; Hu et 
al., 2017). $T_{\max }$ can transfer energy to crops and affect crop transpiration rate. WS determines the transfer of water vapor in the air, which has influence on the atmospheric evapotranspiration. $\mathrm{SH}$ affects the amount of solar radiation during wheat growth period, solar radiation is the energy of soil water vaporization and crop transpiration, which can directly determine the amount of $E T$. $R H$ indicates how high the water vapor saturation in the air is. The higher the water saturation is, the less water vapor can be contained in the air for crop transpiration and soil water evaporation, which leads to the interannual variation of wheat water demand opposite to that of relative humidity. Moreover, the attribution analysis suggested that daily average maximum temperature and relative humidity was the most influential factor to the $E T$, followed by the sunshine duration and wind speed (Fig. 6). Wang et al. (2017) considered suggested the decreasing trend of ETo in Huang-Huai-Hai region was mainly governed by significant decrease in sunshine, which was quite different with this study. The results of this study are basically consistent with the conclusions of Yang et al. (2012) and Liu et al. (2005). Due to the differences in the regional scope, research period and spatial dimensions, there are also some differences. Above all, the variability of $E T$ is a synthesis process of climatic variables change. The $T_{\max }$ rise may lead to increase of $E T$ while the decrease of $W S$ and $S D$ and the increase of $R H$ potentially cause the decrease. This study reveals the descent rate of $W S$ and $S D$ in study during 1969-2019 was higher than the increase rate of $T_{\max }$ and decrease of $R H$, resulting in decreasing trend of $E T$.

\section{Interannual variation of main meteorological factors}

In order to study the interannual variation of the above four meteorological factors, the linear tendency rate of meteorological factors with time was calculated (Table 3). From 1969 to 2019 , the $T_{\max }$ showed a very significant upward trend, while the $R H$, WS and $S H$ showed a very significant downward trend. The change trend of the research results was similar to that of $T_{\max }(0.045), R H\left(7 \mathrm{e}^{-6}\right)$ and $W S$ (-0.019) obtained by Wang et al. (2019) using the Sen's slope estimator in Eastern China during 1979-2015.

Table 3. Propensity rate of meteorological factors during the growing period of winter wheat

\begin{tabular}{c|c|c|c|c}
\hline Factor & $\boldsymbol{T}_{\max }$ & $\boldsymbol{R H}$ & $\boldsymbol{W S}$ & $\boldsymbol{S H}$ \\
\hline Coefficients & 0.32 & -0.04 & -0.45 & -0.29 \\
\hline
\end{tabular}

It can be seen from Fig. 8 that the interannual variation characteristics of wheat water requirement and $T_{\max }, W S$ and $S H$ in Shandong Province from 1969 to 2019 were generally consistent, but contrary to the interannual variation characteristics of $R H$. This was consistent with the results of sensitivity analysis. Combined with the results in Table 3, it can be analyzed that the change of ET is the comprehensive performance of ET increase caused by temperature rise and decrease of ET caused by wind speed decrease. This is consistent with Wang's (2019) point of view that since the 1990s, a region greatly influenced by $W S$ is Shandong, where the impact on $E T_{0}$ of $T_{\max }$ is counteracted by the largest decrease in WS to a great extent. At the same time, a research suggested that the change of $S H$ was the major factor influencing the variability of $E T_{0}$, followed by $W S, R H$ and $T$ in the Yellow River Basin. 

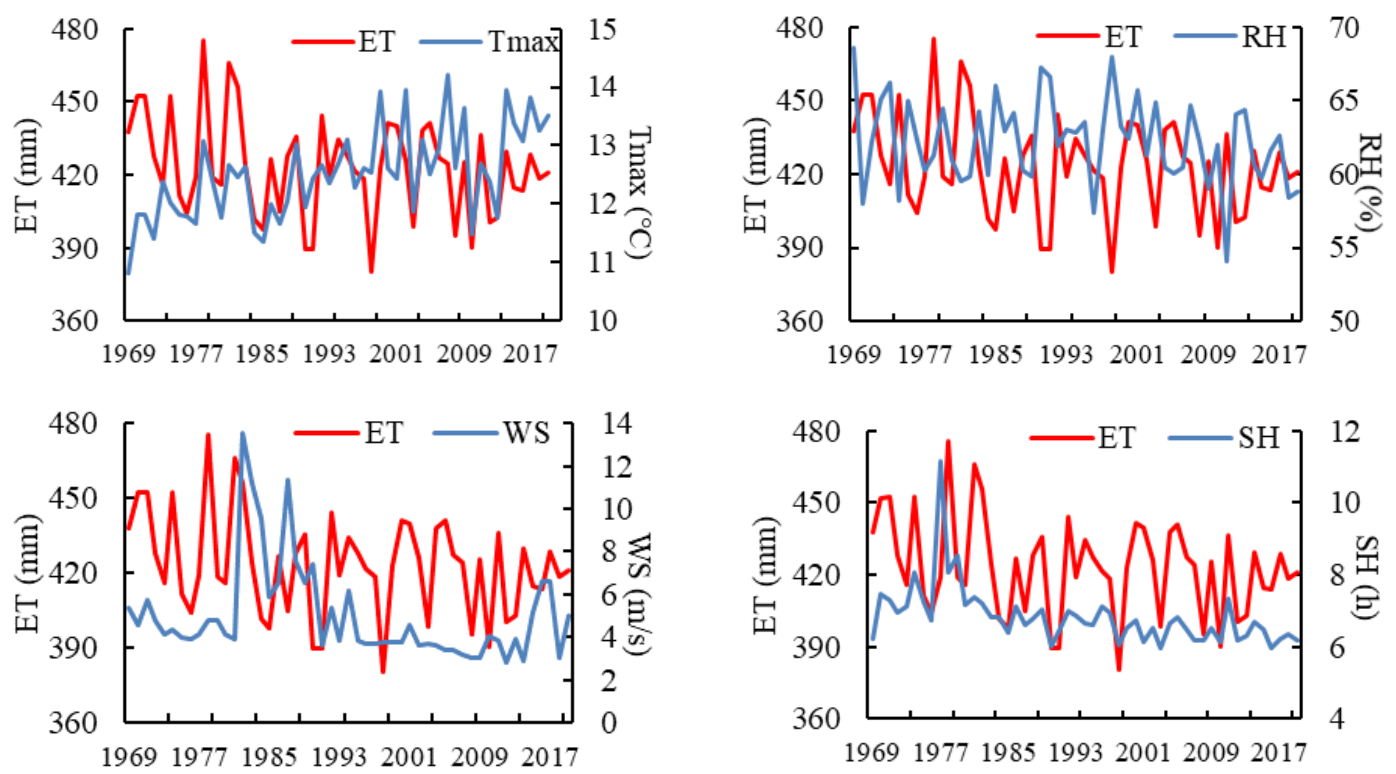

Figure 8. Variation characteristics of meteorological factors and water requirement of winter wheat during growth period

\section{Changes of winter wheat yield under the background of climate change}

ET variability under different climatic conditions may produce either positive or negative effects on crop yield per unit area. In spite of droughts caused by abnormal climate change, wheat yields in Shandong have been increasing in the past 20 years (Fig. 9), implying that the changing ET in Shandong Province played a negligible role in agriculture, which corroborates with the extant literature (Piao et al., 2010). He indicated that on a countrywide basis-the consequences of recent climate change on agriculture have been limited both because climate trends remained moderate compared to natural variability, and because technological progress has brought more than all benefits, in particular improved agricultural practice.
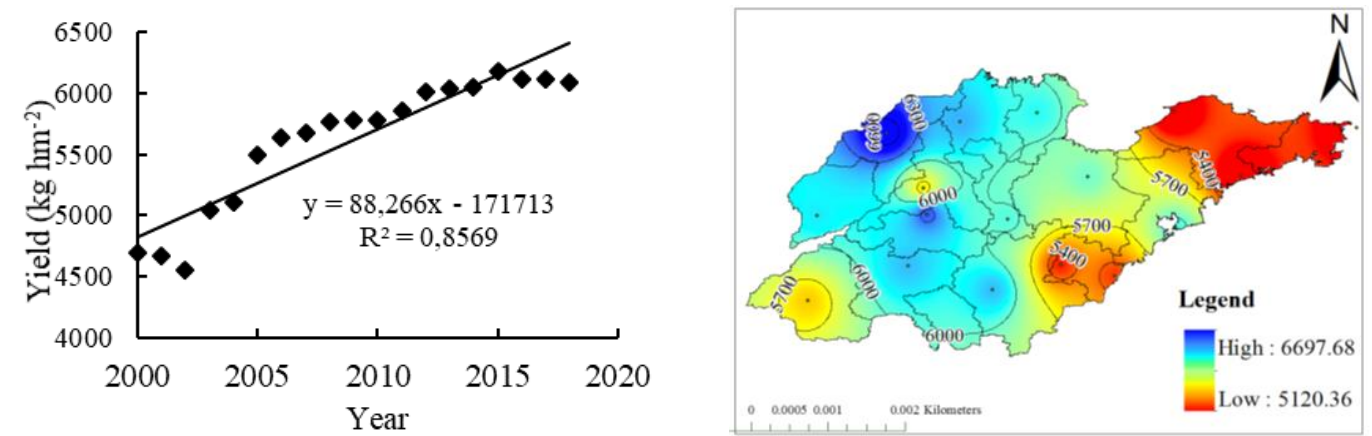

Figure 9. Distribution of winter wheat yield in Shandong Province from 2000 to 2018

The results showed that wheat yield increased year by year regardless of the fluctuation of $E I, P_{e}$ and $I R$, which may be due to the effect of supplementary irrigation on yield. For example, although the long-term tendency of $I R$ was declining for winter wheat, a large 
amount of groundwater was consumed by winter wheat annually in the northern Shandong to maintain high yield, which represented the most important factor for groundwater drawdowns. In addition, the increasing grain yield may mainly benefit from technological progress, such as irrigation system improving and seed amelioration. However, the increasing trend of ET may be large enough in some local regions to offset a significant portion of the increases in average yields that arose from technological progress (Lobell et al., 2011). For example, the increasing ET in western Jiaodong Peninsula induced by humidity reduction and temperature increment may enhance wheat water stress, resulting in greater water requirements for agriculture production and causing reduction in agriculture yield (Fig. 9). Several studies have described that the wheat cultivars renewal and improved crop management practices have offset the negative effects of climatic change on yield (Tao et al., 2012; Wang et al., 2012).

Building the climate-wheat yield relationship without considering the management effects have been large enough to be worthy of attention. Many scholars attempted to differentiate the effects of management and climate change on the crop yield. For example, a research showed that the increase in temperature increased winter wheat yield by 3.0-6.0\% in northern part of the NCP during 1980-2009 (Xiao and Tao, 2014). At the same time, Xiong et al. (2012) found that wheat showed reduced yield (-9.7\%) owing to climate factors, whilst offset by $\mathrm{CO}_{2}$ fertilization (overall change $0.9 \%$ ) in China during 1961-2010. Even, Liu et al. (2016) showed that at global and national scales, global wheat yield was projected to decline between $4.1 \%$ and $6.4 \%$ with a $1{ }^{\circ} \mathrm{CF}$ global temperature increase. It is reported that in the future, the temperature, precipitation and solar radiation in the North China Plain will change significantly (Liu et al., 2018). Therefore, a detailed analysis of climate change and wheat response is essential for wheat growth and management adaptation.

\section{Conclusion}

Under the background of climate change, water shortage is becoming more and more serious in North China in recent years. Improve irrigation management system and stabilizing the yield of crops have become the main production objectives in similar areas. Therefore, understanding of ET of crop in present situation and development trend, and analysis the influence reason is still the scholars concern.

Based on meteorological data from 15 prefecture-level cities in Shandong Province, this paper used the Penman-Monteith formula and crop coefficient method to determine the water requirements of the winter wheat. To a certain extent, it improved the calculation accuracy of water demand and water shortage, which was of great significance for reasonable guidance of wheat irrigation in Shandong Province.

A temporal analysis of the entire region indicated that a turning point occurred in 1984 for the temporal variability of ET. A spatial analysis of the entire region indicated that the $E T, I R$, and $A I$ were the largest on the northwestern Shandong and displayed a decreasing trend from northwest to southeast. Additionally, the ET decreased in the western Shandong, and the ET in the rest of the area increased with a trend of 0-2 mm decade ${ }^{-1}$. And the overall spatial pattern of the trend in $I R$ was similar to that of the trend in ET. The northwest of Shandong has large evaporation and relatively less precipitation, which is the driest climate area and high drought risk area in Shandong.

In the sensitivity analysis of $E T$ of winter wheat to its influencing factors, the $T_{\max }$ was the major factor dominating variability of $E T$ in Shandong, followed by $R H, S H, W S$ and 
$T_{\min }$, respectively. Sensitivity analysis of the $E T$ revealed that the $T_{\max }$ was the most positively correlated with the $E T$ among all the meteorological factors, with sensitivity coefficient of 0.3563 , whereas the meteorological factor with the maximum negative correlation was $R H$, with sensitivity coefficient of -0.3351. Significant declines of WS and $S H$ were responsible for the decrease of $E T$ in the entire Shandong from 1969 to 2019 while the increase of $T_{\max }$ and the decrease of $R H$ contributed to the enhancement of $E T$.

In this study, factors influencing the irrigation requirements of crops were analysed only from a meteorological point of view. With regard to global climate change anomalies, the long-term agricultural water management should be adopted for the continued development. Furthermore, it is necessary to further study the impacts of various agricultural technologies throughout the region to provide a more accurate scientific basis for water management in Shandong farmland.

Acknowledgements. This project was jointly supported by Provincial water conservancy research and technology promotion project of Shandong Province (SDSLKY201803).

\section{REFERENCES}

[1] Allen, R. G., Pereira, L. S., Raes, D., Smith, M. (1998): Crop evapotranspiratione guidelines for computing crop water requirements. - FAO Irrigation and Drainage Paper 56: $1-15$.

[2] Cao, Y. Q., Li, W. J., Zhu, M. M. (2018): Temporal and spatial characteristics of water deficit of winter wheat and cotton in Hebei Province. - Research of Soil and Water Conservation 25(06): 348-356+364+416-417.

[3] Deng, Y., Jiang, W., He, B., Chen, Z., Jia, K. (2018): Change in intensity and frequency of extreme precipitation and its possible teleconnection with large-scale climate index over the China from 1960 to 2015. - Journal of Geophysical Research: Atmospheres 123: 20682081.

[4] Döll, P., Stefan, S. (2002): Global modeling of irrigation water requirements. - Water Resource Research 38(4): 8-1-8-10.

[5] Dong, C., Yang, X., Yang, J., Xie, W., Ye, Q., Zhao, J., Li, K. (2013): The temporal variation characteristics and spatial distribution laws of drought of spring maize in Northern China. - Scientia Agricultura Sinica 46: 4234-4245.

[6] Fan, Z. X., Thomas, A. (2018): Decadal changes of reference crop evapotranspiration attribution: Spatial and temporal variability over China 1960-2011. - Journal of Hydrology 560: 461-470.

[7] Gao, J. Q., Yang, X. G., Zheng, B. Y., Liu, Z. J., Zhao, J., Sun, S., Li, K. N., Dong, C. Y. (2019): Effects of climate change on the extension of the potential double cropping region and crop water requirements in northern China. - Agricultural and Forest Meteorology 268: 146-155.

[8] Gu, X., Zhang, Q., Singh, V. P., Shi, P. (2017): Changes in magnitude and frequency of heavy precipitation across China and its potential links to summer temperature. - Journal of Hydrology 547: 718-731.

[9] He, B., Liu, Z. J., Yang, X. G., Sun, S. (2017): Temporal and spatial variations of agrometeorological disasters of main crops in China in a changing climate ( II ): drought of cereal crops in Northwest China. - Chinese Journal of Agrometeorology 38(1): 31-41.

[10] Hu, Q., Dong, B., Pan, X. B., Wang, X. X., Wei, P., Zhao, H. H., Zhang, X. T. (2017): Spatiotemporal variation and causes analysis of dry-wet climate at different time scales in North China Plain Chinese. - Journal of Agrometeorology 38(05): 267-277. 
[11] Liang, L. Q., Li, L. J., Liu, Q. (2010): Temporal variation of reference evapotranspiration during 1961-2005 in the Taoer River basin of Northeast China. - Agricultural and Forest Meteorology 150: 298-306.

[12] Liu, X. Y., Lin, E. D. (2004): Impact of climate change on water requirement of main crops in North China. - Journal of Hydraulic Engineering 2: 77-82.

[13] Liu, X. Y., Li, Y. Z., Hao, W. P. (2005): Trend and causes of water requirement of main crops in North China in recent 50 years. - Transactions of the Chinese Society of Agricultural Engineering 10: 155-159.

[14] Liu, Q., Mei, X. R., Yan, C. G., Ju, H., Yang, J. Y. (2013): Dynamic variation of water deficit of winter wheat and its possible climatic factors in Northern China. - Acta Ecologica Sinica 33(20): 6643-6651.

[15] Liu, B., Asseng, S., Müller, C., Ewert, F., Elliott, J., et al. (2016): Similar estimates of temperature impacts on global wheat yield by three independent methods. - Nature Climate Change 6: 1130-1136.

[16] Liu, Q., Yan, C. G., Ju, H., Garré, S. (2018): Impact of climate change on potential evapotranspiration under a historical and future climate scenario in the Huang-Huai-Hai Plain, China. - Theoretical and Applied Climatology 132(1): 387-401.

[17] Lobell, D. B., Schlenker, W., Costa-Roberts, J. (2011): Climate trends and global crop production since 1980. - Science 333(6042): 616-620.

[18] Ma, J. H., Liu, Y., Yang, X. G., Wang, W. F., Xu, C. Y., Zhang, X. Y. (2010): Characteristics of climate resources under global climate change in the North China Plain. - Acta Ecologica Sinica 30(14): 3818-3827.

[19] Piao, S. L., Ciais, P., Huang, Y., Shen, Z. H., Peng, S. S., Li, J. F., Zhou, L. P., Liu, H. Y., Ma, Y. C., Ding, Y. H., Friedlingstein, P., Liu, C. Z., Tan, K., Yu, Y. Q., Zhang, T. Y., Fang, J. Y. (2010): The impacts of climate change on water resources and agriculture in China. - Nature 467: 43-51.

[20] Shen, Y. J., Li, S., Chen, Y. N., Qi, Y. Q., Zhang, S. W. (2013): Estimation of regional irrigation water requirement and water supply risk in the arid region of northwestern China 1989-2010. - Agricultural Water Management 128(1): 55-64.

[21] Smith, M. (1992): Cropwat: a computer program for irrigation planning and management. - FAO Irrigation and Drainage Paper 46: 1-123.

[22] Sun, S., Yang, X. G., Li, K. N., Zhao, J., Ye, Q., Jie, W. J., Dong, C. Y., Liu, H. (2013): Analysis of spatial and temporal characteristics of water requirement of winter wheat in China. - Transactions of the Chinese Society Agricultural Engineering 29(15): 72-82.

[23] Tao, F., Yokozawa, M., Hayashi, Y., Lin, E. (2003): Changes in agricultural water demands and soil moisture in China over the last half-century and their effects on agricultural production. - Agricultural and Forest Meteorology 118: 251-261.

[24] Tao, F., Zhang, S., Zhang, Z. (2012): Spatiotemporal changes of wheat phenology in China under the effects of temperature, day length and cultivar thermal characteristics. - European Journal of Agronomy 43: 201-212.

[25] Vicente-Serrano, S. M., Beguería, S., López-Moreno, J. I. (2010): A multiscalar drought index sensitive to global warming: the standardized precipitation evapotranspiration index. - Journal of Climate 23: 1696-1718.

[26] Villarini, G., Smith, J. A., Serinaldi, F., Ntelekos, A. A., Schwarz, U. (2012): Analyses of extreme flooding in Austria over the period 1951-2006. - International Journal of Climatology 32(8): 1178-1192.

[27] Wang, J., Wang, E., Yang, X., Zhang, F., Yin, H. (2012): Increased yield potential of wheat-maize cropping system in the North China Plain by climate change adaptation. Climatic Change 113: 825-840.

[28] Wang, Z., Xie, P., Lai, C., Chen, X., Wu, X., Zeng, Z., Li, J. (2017): Spatiotemporal variability of reference evapotranspiration and contributing climatic factors in China during 1961-2013. - Journal of Hydrology 544: 97-108. 
[29] Wang, Z., Ye, A., Wang, L., Liu, K., Cheng, L. (2019): Spatial and temporal characteristics of reference evapotranspiration and its climatic driving factors over china from 1979-2015. - Agricultural Water Management 213: 1096-1108.

[30] Wu, D., Fang, S. B., Li, X., He, D., Zhu, Y. C., Yang, Z. Q., Xu, J. X., Wu, Y. J. (2019): Spatial-temporal variation in irrigation water requirement for the winter wheat-summer maize rotation system since the 1980s on the North China Plain. - Agricultural Water Management 214: 78-86.

[31] Wu, Y. C., Sun, P., Li, N., Sun, M., Yang, M. G., Jiang, M. M. (2020): Characteristics of water need and shortage for winter wheat on Northern Anhui Plain in the past 60 years. Journal of Xichang University (Natural Science Edition) 34(2): 6-12+128.

[32] Wu, Y., Li, X., Ma, Z. Y., Sun, S. H., Jia, R. B. (2020): Water resources carrying capacity evaluation based on support vector machine in Shandong Province. - Journal of Safety and Environment 10: 1-10.

[33] Xiao, D., Tao, F. (2014): Contributions of cultivars, management and climate change to winter wheat yield in the North China Plain in the past three decades. - European Journal of Agronomy 52: 112-122.

[34] Xiong, W., Holman, I., Lin, E., Conway, D., Li, Y., Wu, W. (2012): Untangling relative contributions of recent climate and $\mathrm{CO}_{2}$ trends to national cereal production in China. Environmental Research Letters 7: 044014.

[35] Xu, Z. H., Han, M. (2018): Spatio-temporal distribution characteristics of drought in Shandong Province and it relationship with ENSO. - Chinese Journal of Eco-Agriculture 26(08): 1236-1248.

[36] Yang, X. L., Song, W. Z., Wang, H., Shi, Q. H., Chen, F., Zhu, Q. Q. (2012): Spatiotemporal variations of winter wheat water requirement and climatic causes in Huang-HuaiHai Farming Region. - Chinese Journal of Eco-Agriculture 20(03): 356-362.

[37] Yin, X. G., Olesen, J. E., Wang, M., Öztürk, I., Chen, F. (2016): Climate effects on crop yields in the Northeast Farming Region of China during 1961-2010. - The Journal of Agricultural Science 154: 1190-1208.

[38] Yuan, Z., Yan, D. H., Yang, Z. Y., Yin, J., Yuan, Y. (2015): Temporal and spatial variability of drought in Huang-Huai-Hai River Basin, China. - Theoretical and applied Climatology 122: 755-769.

[39] Zhang, K. X., Pan, S. M., Zhang, W., Xu, Y. H., Cao, L. G., Hao, Y. P., Wang, Y. (2015): Influence of climate change on reference evapotranspiration and aridity index and their temporal-spatial variations in the yellow river basin, china, from 1961 to 2012. Quaternary International 380-381: 75-82.

[40] Zhang, C., Chen, X. X., Li, Y., Ding, W., Fu, G. T. (2018): Water-energy-food nexus: concepts, questions and methodologies. - Journal of Cleaner Production 195: 625-639.

[41] Zheng, C., Wang, Q. (2015): Spatiotemporal pattern of the global sensitivity of the reference evapotranspiration to climatic variables in recent five decades over China. Stochastic environmental research and risk assessment 29: 1937. 